\title{
Modification of Focal Cerebral Ischemia by Cardiac Output Augmentation
}

\author{
Ted S. Keller, M.D., John E. MCGillicuddy, M.D., Virginia A. LaBond, M.S., \\ AND GLENN W. KINDT, M.D. \\ Section of Neurosurgery, University of Michigan Medical Center, Ann Arbor, Michigan 48109
}

Submitted for publication March 20, 1984

\begin{abstract}
Intravascular volume expansion has been employed successfully for treatment of ischemic stroke from cerebral vasospasm and from cerebrovascular occlusive disease. The physiologic mechanism responsible for this success has not previously been delineated in controlled experimentation. The objective of this investigation was to delineate the effects of cardiac output and of hemodilution in a primate model of focal cerebral ischemia. Two groups of anesthetized rhesus monkeys received extensive cardiovascular monitoring, and local cerebral blood flow (ICBF) was determined in both ischemic and nonischemic brain regions by the hydrogen clearance method. Both groups were subjected to unilateral middle cerebral artery occlusion. One group then underwent blood volume expansion with Dextran 40 (cardiac output augmentation), and one group underwent isovolemic hemodilution with Dextran 40 , cardiac output being maintained constant. Significant increases in $\mathrm{ICBF}$ occurred in ischemic regions only and occurred only in response to augmentation of cardiac output. Isovolemic hemodilution failed to produce any changes in ICBF. This investigation indicates that ischemic brain regions are selectively vulnerable to alterations in cardiac output, these effects being independent of alterations in blood pressure. Blood viscosity changes may play only a minor role. This study strongly suggests an important role of intravascular volume expansion and cardiac output augmentation in treatment of acute ischemic stroke. (c) 1985 Academic Press, Inc.
\end{abstract}

\section{INTRODUCTION}

Intravascular volume expansion has become a widely employed and highly successful adjunct to treatment of the ischemic syndrome from cerebral vasospasm in patients with subarachnoid hemorrhage from ruptured intracranial aneurysms $[12,13,18,19]$. Volume expansion with colloid agents has also been successful in a number of preliminary clinical trials on patients with acute ischemic stroke of occlusive origin from atheromatous cerebrovascular disease [18, 20, 29]. How an increase in circulating blood volume alone should be successful in elevating blood flow to ischemic brain regions is perplexing since an increase in systemic arterial pressure often did not occur with such treatment $[18,19]$.

Some investigators have speculated that blood viscosity alterations which occur when blood volume is expanded with various colloid agents could be responsible for rheologic changes to ischemic brain and have, therefore, used this theory as a rationale for their treat- ment [4, 7-9, 25, 29-31]. However, other investigators have suggested that cardiac output changes occurring with intravascular volume expansion and with other pharmacologic intcrvention during cerebral ischemia might be responsible for the success of this treatment $[19,20,22,32]$. It is well known that acute blood volume expansion produces a hyperdynamic cardiovascular response, often with marked increases in cardiac output as would be predicted by the Frank-Starling law governing cardiac function [6, 21]. Why an augmentation of cardiac output alone should cause an increase in blood flow to ischemic brain regions was confusing since it was unclear where cardiac output should fit into classic equations governing cerebral blood flow. If ischemic brain regions were that sensitive to alterations in cardiac output, however, the implications for treatment of acute ischemic stroke from many causes could be quite profound.

This study was undertaken to investigate the effects of intravascular volume expansion with 
a colloid agent on cardiac output and on local blood flow to both ischemic and nonischemic brain regions in a primate model of focal cerebral ischemia. Control studies were included in an attempt to separate the effects of cardiac output changes from those of blood viscosity alterations alone on local cerebral blood flow in this model.

\section{METHODS}

General animal preparation and monitoring procedures. Adult rhesus monkeys (Macaca mulatta) of both sexes were utilized during the course of the experimental procedures. All animals were initially sedated with intramuscular ketamine hydrochloride $(10 \mathrm{mg} / \mathrm{kg})$ to facilitate endotracheal intubation and placement of a peripheral intravenous catheter. Body temperature was maintained constant with a heating pad wrapped about the animal's torso. Following intravenous induction of sodium pentobarbital anesthesia $(20 \mathrm{mg} / \mathrm{kg})$, all animals were pharmacologically paralyzed with pancuronium $(0.1 \mathrm{mg} / \mathrm{kg})$ and were ventilated with a volume respirator using a gas mixture composed of $40 \%$ oxygen, $60 \%$ nitrogen. Ventilatory parameters were adjusted to maintain a stable $p \mathrm{CO} 2$ between 35 and $40 \mathrm{~mm} \mathrm{Hg}$.

Bilateral femoral cutdowns were performed for placement of an arterial catheter and a long 16-gauge catheter for central venous pressure monitoring and for injection of dye for cardiac output determinations. A 5 French double-lumen flow-directed catheter was then floated into the pulmonary artery via the other femoral vein for continuous pulmonary arterial pressure recordings and for intermittent pulmonary arterial wedge pressure recordings.

EKG, systemic arterial pressure, pulmonary arterial pressure, heart rate, and rectal temperature were continuously monitored on a paper strip recorder. Arterial blood gases and hematocrit were determined intermittently throughout all studies by sampling from the aortic catheter. Cardiac output determinations were performed with the use of an elcctronic cardiac output computer utilizing the dye dilution method.
Intravascular volume expansion with Dextran 40. Following baseline cardiovascular parameter recordings and hematocrit determinations, those animals underwent incremental blood volume expansion with 20 to $50 \mathrm{ml}$ boluses of $10 \%$ Dextran 40 which had been warmed in a water bath to $37^{\circ} \mathrm{C}$. Several minutes following each injection, repeat cardiac output and hematocrit determinations were obtained. Additional boluses of dextran were given at 30-min intervals until cardiac output plateaued at its highest level for each animal.

Isovolemic hemodilution with Dextran 40. Following baseline hematocrit and cardiac output determinations, an exchange transfusion technique was employed in which $10 \%$ Dextran 40 was injected into the central venous line while arterial blood was withdrawn at a similar rate through the aortic catheter. Equivalent volumes of dextran and whole blood were thereby determined in a "trial and error" fashion such that cardiac output would remain at or near control values. Cardiac output and hematocrit determinations were performed after each exchange transfusion.

Local CBF determinations. All animals employed in the definitive studies on cerebral ischemia underwent placement of four burr holes in standard cranial locations following reflection of the scalp and temporalis muscles (Fig. 1). Electrodes for hydrogen clearance determination were fashioned from No. 30 platinum wire having a diameter of $0.254 \mathrm{~mm}$, such that a bared tip of 1.5 to $2.0 \mathrm{~mm}$ preceded an insulating ball of adhesive material. The dura mater in each location of CBF determination was punctured with the electrode until the insulating ball rested on the surface of the dura mater.

The hydrogen clearance method for determinations of cerebral blood flow was employed according to the techniquc and instrumentation of Willis et al. [28] and each determination was preceded by the delivery of 8 to $10 \%$ hydrogen into the inspired gas mixture until tissue saturation appeared.

Standard sites for determination of ICBF are illustrated in Fig. 1. The two nonischemic regions selected were the left frontal convexity 


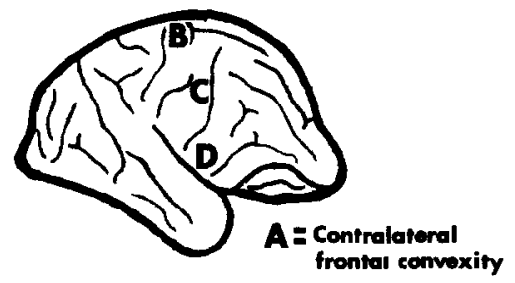

FIG. 1. Areas for measurement of local cerebral blood flow.

(contralateral hemisphere) and the right parasagittal frontal region, an area supplied predominantly by the anterior cerebral artery. Two areas within the distribution of the right middle cerebral artery (MCA) were also selected, one in the frontal opercular region and one in the frontal convexity region. These two ischemic regions were studied to delineate any differential responses within the middle cerebral artery territory since the expcriments of Symon et al. [27], had documented differential reductions in blood flow in these two locations in response to MCA occlusion.

ICBF determinations were performed in both experimental and control animals prior to MCA occlusion, following MCA occlusion, and following each dextran bolus or each exchange transfusion of dextran and blood.

$M C A$ exposure and occlusion. A transorbital technique [10] was performed for exposure of the right middle cerebral artery, using microsurgical technique. At the appropriate time, this artery was occluded at its origin with an aneurysm clip. Following MCA occlusion, the orbit was packed loosely with saline-moistened cotton balls.

Examination of brains. At the conclusion of each experimental or control study involving cerebral ischemia, the animal was sacrificed with an overdosage of barbiturate. The brains were removed, and all were inspected to ensure adequacy of right middle cerebral artery occlusion and to inspect areas of electrode placement. All brains were preserved in formaldehyde and were later grossly inspected with coronal slicing.

Statistical analysis of results. Local CBF data and cardiovascular data were compiled, and the means and standard deviations of each group were computed. Comparisons of data within each group and between the two groups were made using a two-tailed $t$ test.

\section{RESULTS}

\section{Intravascular Volume Expansion with Dextran 40-Circulatory Effects}

Data in Table 1 display that incremental volume expansion with intravenous boluses of Dextran 40 could be performed rather consistently without any significant alterations in mean arterial pressure (less than 10\%). Each dextran bolus was promptly followed by an increase in cardiac output and by an increase in pulmonary arterial wedge pressure. Hematocrit steadily decreased, as would be expected, throughout the course of volume expansion. Cardiac output continued to rise with each dextran bolus until a maximal level was reached. Increases in cardiac output were apparently mediated by an increase in stroke volume in all animals since heart rate usually remained stable or fell slightly during volume expansion. The amount of dextran required in these animals to maximize cardiac output averaged $25 \mathrm{ml} / \mathrm{kg}$. Cardiac output was also observed to maximize between pulmonary wedge pressures of 12 to $24 \mathrm{~mm} \mathrm{Hg}$ with a mean of $17 \mathrm{~mm} \mathrm{Hg}$.

\section{Isovolemic Hemodilution-Circulatory Effects}

Control animals in this study underwent exchange transfusions of equivalent volumes of Dextran 40 and whole blood. Thus, a state of isovolemic hemodilution could be achieved in which cardiac output would remain constant, though hemodilution to levels similar to those achieved in experimental animals would be produced. This state could be produced by simultaneous infusion of 1 vol dextran and withdrawal of 2 vol whole blood.

Cardiovascular data for control animals are also displayed in Table 1. Mean arterial pressure also remained stable in individual control animal studies. However, the mean arterial pressure on the average was significantly lower 
TABLE 1

CARDIOVASCUlar EFFECTS: EXPERIMENTAL vs CONTROL ANIMALS

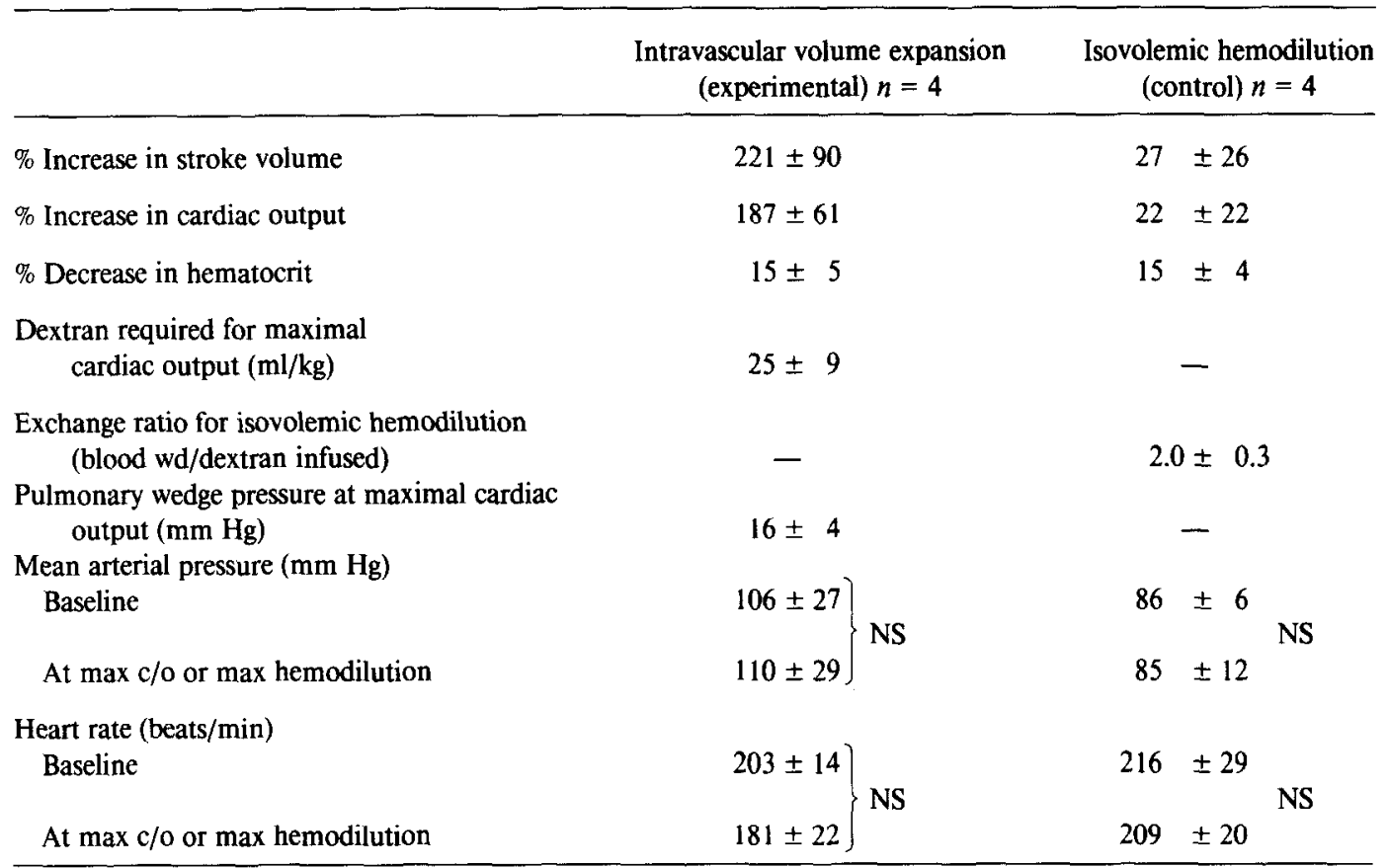

in this control group than for the experimental group. Cardiac output remained near prehemodilution levels throughout the course of the experiments. Mean decrease in hematocrit was identical to that seen in experimental animals.

Two control animals underwent reinfusion of withdrawn heparinized blood after maximal hemodilution, and it was noted that cardiac output would then tend to increase after these infusions.

\section{Unilateral MCA Occlusion-Effect on Local CBF}

Preocclusion values of local blood flow were high in all areas measured and were certainly within the range of gray matter blood flow values which have been previously reported [27]. Immediately following clip occlusion of the right middle cerebral artery, local blood flow fell markedly in the right frontal convexity and in the right frontal opercular region. Reductions in local $\mathrm{CBF}$ were usually of similar magnitude in these two areas as displayed in Tables 2 and 3. Local CBF in the right frontal convexity fell to $41 \pm 5 \%$ and to $44 \pm 20 \%$ of preocclusion values in experimental and control animals, respectively. Local CBF in the right frontal opercular region fell to $45 \pm 12 \%$ and to $38 \pm 23 \%$ in experimental and control animals, respectively. Statistical analysis reveals no significant differences in the depth of ischemia for the two groups. Responses of individual animals in both experimental and control groups can be seen in Figs. 2 and 3. Local CBF to the contralateral hemisphere and to the ipsilateral parasagittal region was little altered by MCA occlusion.

\section{Intravascular Volume Expansion-Effects of Cardiac Output Augmentation on Local CBF}

The effects of intravascular volume expansion on local CBF following right MCA occlusion for each experimental animal are charted in Fig. 2. During the course of volume expansion with dextran, blood flow to nonischemic regions ( $a$ and $b$ ) remained relatively stable. In all experimental animals, however, 

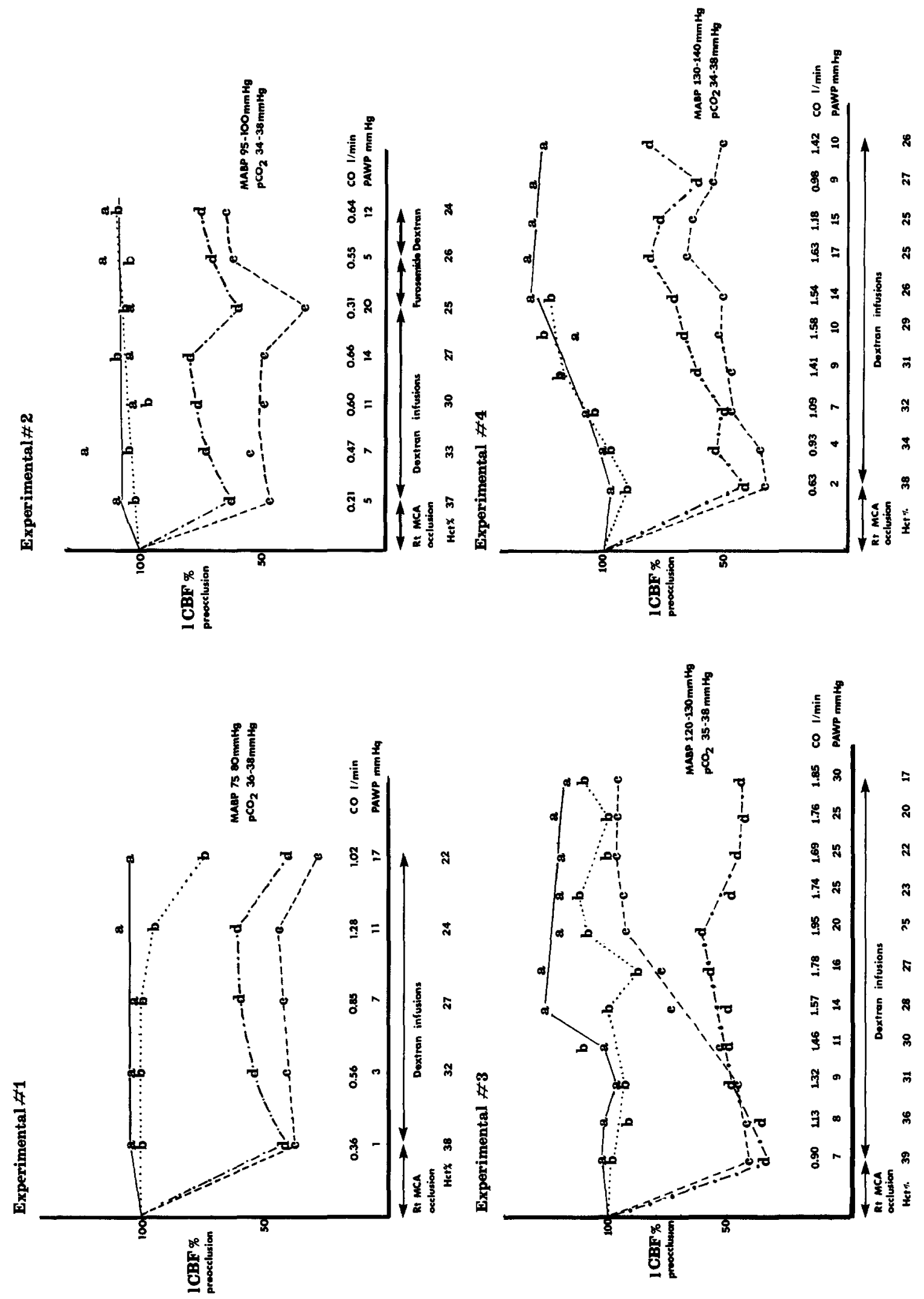
TABLE 2

LOCAL CBF-EFFECT OF Right MCA OCCLUSION and INTRAVASCULAR Volume EXPANSION

\begin{tabular}{|c|c|c|c|c|c|}
\hline \multirow[b]{2}{*}{ Region } & \multirow[b]{2}{*}{ Preocclusion } & \multicolumn{2}{|c|}{ Postocclusion } & \multicolumn{2}{|c|}{$\begin{array}{l}\text { Volume expansion } \\
\text { maximal cardiac output }\end{array}$} \\
\hline & & Local CBF & $\%$ Preoccl. & Local CBF & $\%$ Preoccl. \\
\hline $\begin{array}{l}\text { Left frontal convexity } \\
\text { (a) } N=4\end{array}$ & $65 \pm 25$ & $67 \pm 26$ & $103 \pm 6$ & $78 \pm 31$ & $119 \pm 13$ \\
\hline $\begin{array}{l}\text { Right parasagittal } \\
\text { (b) } N=4\end{array}$ & $56 \pm 18$ & $55 \pm 19$ & $98 \pm 7$ & $63 \pm 23$ & $112 \pm 11$ \\
\hline $\begin{array}{l}\text { Right frontal convexity } \\
\text { (c) } N=4\end{array}$ & $\begin{array}{r}39 \pm 13 \\
P=\end{array}$ & 06 & $41 \pm 5$ & $24 \pm 8$ & $62 \pm 24$ \\
\hline $\begin{array}{l}\text { Right frontal operculum } \\
\text { (d) } N=4\end{array}$ & $\begin{array}{r}77 \pm 36 \\
P=\end{array}$ & $34 \pm 15$ & $45 \pm 12$ & .04 & $70 \pm 12$ \\
\hline
\end{tabular}

Note. Local CBF expressed as mean in $\mathrm{ml} / 100 \mathrm{~g} / \mathrm{min} \pm$ standard deviation.

there was usually a steady, step-wise increase in local CBF to ischemic regions ( $c$ and $d$ ). The responses of the two ischemic regions was variable, and the opercular region's blood flow tended to increase most consistently and most dramatically with progressive volume expansion.

Particularly interesting responses occurred late in the course of volume expansion in three experimental animals. Experimental monkeys 1 and 2 apparently experienced degrees of congestive heart failure since a drop in cardiac output occurred in congress with progressive elevation of pulmonary wedge pressure. This drop in cardiac output was especially marked in experimental animal 2. Local CBF to ischemic regions fell markedly while there were no changes in local CBF to nonischemic regions. This animal was given $2 \mathrm{mg}$ of furosemide intravenously, and there was prompt elevation of cardiac output and lowering of pulmonary wedge pressure associated with a brisk diuresis. While local CBF in nonischemic regions remained unaltered, there was a prompt restoration of improved blood flow to both ischemic regions. Experimental animal 4 had a spontaneous large diuresis when volume expansion with dextran was delayed. Both pulmonary wedge pressure and cardiac output fell significantly at this point as did ICBF to both ischemic regions.

Compiled local CBF data for all experimental animals is displayed in Table 2. Overall, local CBF tended to rise in all regions, though most markedly in ischemic regions. Blood flow to the right frontal convexity increased from $41 \pm 5 \%$ of preocclusion values to $62 \pm 24 \%$ at maximal cardiac output during volume expansion. This difference, however, was not statistically significant due to the inconsistency of responses in this region with a resultant large standard deviation. These differences in the ischemic frontal operculum, however, were statistically significant with an

FIG. 2. Responses of local cerebral blood flow (ICBF) to right middle cerebral artery (MCA) occlusion and intravascular volume expansion with Dextran 40 . ICBF expressed as percentage (\%) of preocclusion value; $\mathrm{CO}$, cardiac output, expressed as liters per minute $(1 / \mathrm{min})$; PAWP, pulmonary arterial wedge pressure; MABP, mean arterial blood pressure; Hct, hematocrit; (a) left frontal convexity; (b) right parasagittal region; (c) right frontal convexity; (d) right frontal operculum. 

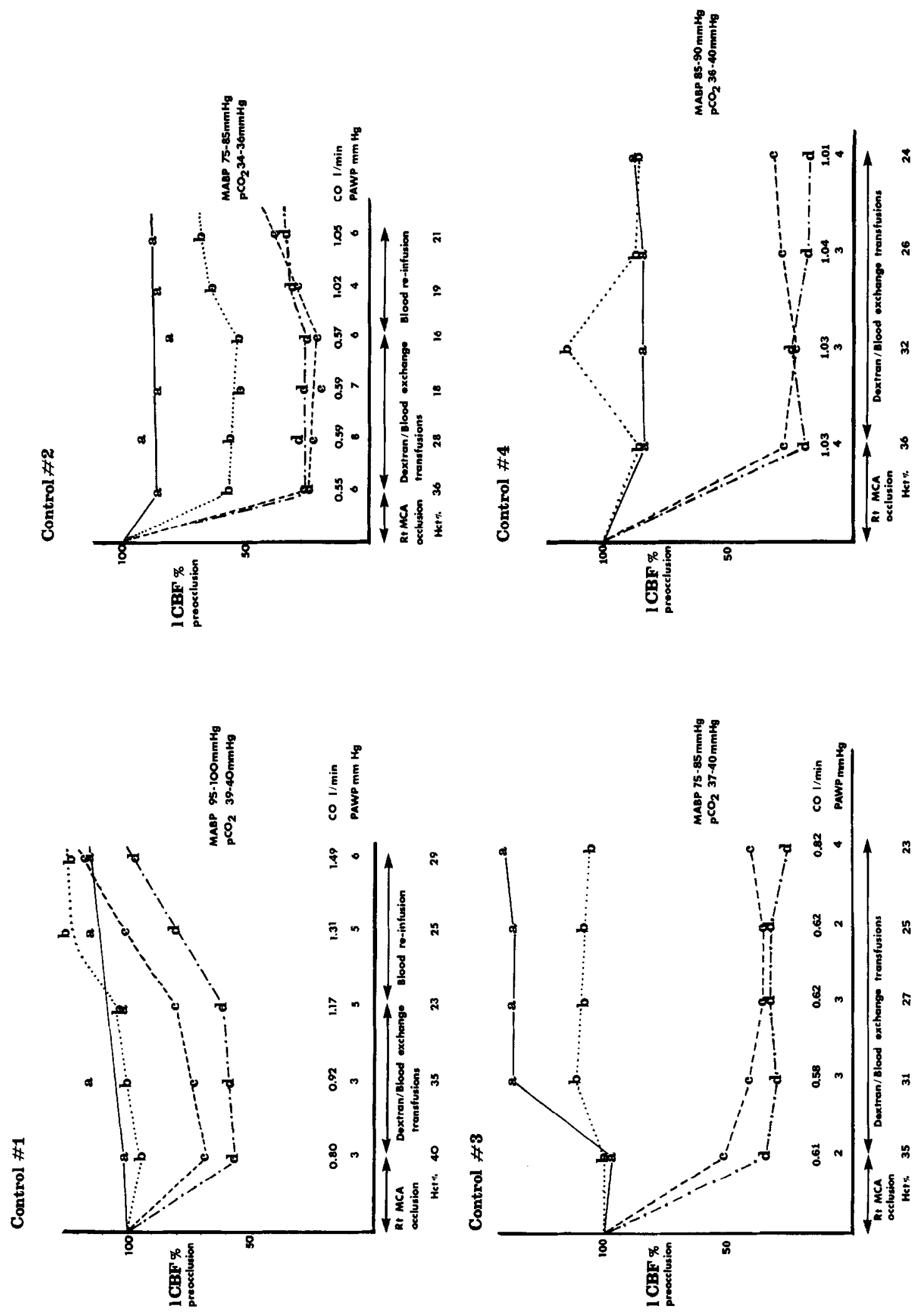
impressive increase in local CBF from 45 $\pm 12 \%$ of its preocclusion value to $70 \pm 12 \%$ at maximal cardiac performance. Differences in local $\mathrm{CBF}$ to nonischemic regions were not statistically significant.

\section{Isovolemic Hemodilution-Effects on Local CBF with Constant Cardiac Output}

Figure 3 illustrates the course of events for the four control monkeys which underwent exchange transfusions of dextran and blood with resultant hemodilution at a constant cardiac output. Stable pulmonary wedge pressures during hemodilution reflected the stable volume status. Local CBF in all regions remained essentially unchanged throughout the course of hemodilution. At the conclusion of the hemodilution period, control animals 1 and 2 underwent reinfusion of their own heparinized blood which had previously been withdrawn. Significant elevations in cardiac output occurred in response to blood reinfusions, and increases in local CBF to ischemic regions occurred as well.

Compiled data for all control animals are presented in Table 3. While there were slight, but insignificant increases in local CBF to nonischemic regions, there were essentially no changes in local CBF to ischemic regions at maximal hemodilution.

\section{Comparison of Experimental and Control Data}

Mean percentage changes in local $\mathrm{CBF}$ from postocclusive values for both experimental and control animals is presented in Table 4. While small increases in local CBF of less than $20 \%$ were observed in nonischemic regions in both groups of animals, there were relatively large mean percentage increases in local CBF to both ischemic regions in response to volume expansion at maximal cardiac performance.
There were not, however, any such increases in local CBF to ischemic regions seen in response to hemodilution without an elevation of cardiac output. The apparent wide difference in local CBF response in the frontal convexity was not statistically significant due to inconsistency of responses seen in experimental animals. A very high statistical significance could be given to the differences in local CBF responses in the ischemic frontal operculum, however.

These observations tend to support the hypothesis that intravascular volume expansion can selectively increase local CBF to ischemic brain regions. This response appears to be most dependent on the augmentation of cardiac output which occurs from infusion of a colloid agent and does not occur if hemodilution without volume expansion is performed. Therefore, it appears that blood viscosity alterations occurring with hemodilution may play a minor role in regulation of local blood flow to ischemic brain. Local CBF to nonischemic brain is little affected by hemodilution whether or not it is performed with an expansion of blood volume.

\section{Postmortem Examination of Brains}

In all experimental and control animals, gross examination of brains confirmed complete clip occlusion of the right middle cerebral artery at its origin from the carotid bifurcation. Findings in coronal sectioning of brains were similar in all experimental and control animals. There was minimal (less than $0.5 \mathrm{~mm}$ ) or no shift of midline structures, and in experimental monkey 1 , there was mild deformity of the right lateral ventricle. The only discernible difference between the two groups of brains was a more striking pallor of the striate nuclei on the right seen in brains of all control animals. These minimal gross patho-

FIG. 3. Responses of local cerebral blood flow (ICBF) to right middle cerebral artery (MCA) occlusion and isovolemic hemodilution with Dextran $40.1 \mathrm{CBF}$ expressed as percentage (\%) of preocclusion value; $\mathrm{CO}$, cardiac output, expressed as liters per minute $(1 / \mathrm{min})$; PAWP, pulmonary arterial wedge pressure; MABP, mean arterial blood pressure; Hct, hematocrit; (a) left frontal convexity; (b) right parasagittal region; (c) right frontal convexity; (d) right frontal operculum. 
TABLE 3

LOCAL CBF-EFFECT OF RIGHT MCA OCCLUSION AND ISOVOLEMIC HEMODILUTION

\begin{tabular}{|c|c|c|c|c|c|}
\hline \multirow[b]{2}{*}{ Region } & \multirow[b]{2}{*}{ Preocclusion } & \multicolumn{2}{|c|}{ Postocclusion } & \multicolumn{2}{|c|}{$\begin{array}{l}\text { Maximal hemodilution } \\
\text { cardiac output constant }\end{array}$} \\
\hline & & Local CBF & $\%$ Preoccl. & Local CBF & $\%$ Preoccl. \\
\hline $\begin{array}{l}\text { Left frontal convexity } \\
\text { (a) } N=4\end{array}$ & $62 \pm 34$ & $54 \pm 34$ & $85 \pm 8$ & $62 \pm 34$ & $101 \pm 28$ \\
\hline $\begin{array}{l}\text { Right parasagittal } \\
\text { (b) } N=4\end{array}$ & $64 \pm 31$ & $56 \pm 35$ & $85 \pm 13$ & $58 \pm 38$ & $90 \pm 27$ \\
\hline $\begin{array}{l}\text { Right frontal convexity } \\
\text { (c) } N=4\end{array}$ & $\begin{array}{r}49 \pm 19 \\
P=\end{array}$ & $50 \pm 7$ & $44 \pm 20$ & $19 \pm 7$ & $45 \pm 27$ \\
\hline $\begin{array}{l}\text { Kight frontal operculum } \\
\text { (d) } N=4\end{array}$ & $75 \pm 25$ & $426 \pm 12$ & $38 \pm 23$ & $23 \pm 11$ & $33 \pm 22$ \\
\hline
\end{tabular}

Note. Local CBF expressed as mean in $\mathrm{ml} / 100 \mathrm{~g}$ min \pm standard deviation.

logic findings are what would be expected from a relatively short duration of ischemia varying between 3 and $6 \mathrm{hr}$ in these studies.

\section{DISCUSSION}

The efficacy of intravascular volume expansion in the acute reversal of neurologic deficits in patients with focal cerebral ischemia has been reported in multiple clinical series $[12,13,18,19]$. Several laboratory investigations have also confirmed that volume expan-

TABLE 4

Mean \% Change in Postocclusive ICBF

\begin{tabular}{lccc}
\hline & $\begin{array}{c}\text { Volume expansion } \\
\text { maximal cardiac } \\
\text { output }\end{array}$ & $\begin{array}{c}\text { Hemodilution } \\
\text { cardiac output } \\
\text { constant }\end{array}$ \\
\hline $\begin{array}{l}\text { Left frontal convexity } \\
\text { (a) }\end{array}$ & $+17 \%$ & $\mathrm{NS}$ & $+18 \%$ \\
$\begin{array}{l}\text { Right parasagittal } \\
\text { (b) }\end{array}$ & $+15 \%$ & $\mathrm{NS}$ & $+5 \%$ \\
$\begin{array}{l}\text { Right frontal convexity } \\
\text { (c) }\end{array}$ & $+51 \%$ & $\mathrm{NS}$ & $-1 \%$ \\
$\begin{array}{l}\text { Right frontal operculum } \\
\text { (d) }\end{array}$ & $+60 \%$ & & $-11 \%$ \\
\hline
\end{tabular}

sion with a colloid agent is capable of selectively increasing local blood flow to ischemic brain regions in both animals $[16,18,30]$ and humans [9] and of reducing infarct size in animals $[4,14,25]$. However, other laboratory models have failed to uphold any beneficial effect of this therapy [17, 23].

A possible mechanism by which intravascular volume expansion alone, without a concomitant increase in cerebral perfusion pressure, could produce an improvement in blood flow to ischemic brain regions has not been clearly delineated in the past. The usual assumption has been that hemodilution and viscosity reduction brought about by infusion of colloid agents such as serum albumin, low molecular weight dextran, mannitol, and glycerol improves blood flow to ischemic regions by reducing aggregation of blood elements and by retarding intravascular "sludging" in such low flow areas $[4,8,9,25,30$, 31]. It has also been proposed that the dehydrating action of some of these agents may diminish perifocal edema and thereby bring about reductions in vascular resistance [25]. Neither of these theories, however, has been confirmed in strictly controlled laboratory investigations. 
Other investigators, however, have suggested that primary improvement in cardiac function which occurs during volume expansion with colloid agents may be responsible for the apparent beneficial results [19, 20, 22]. Patients with focal cerebral ischemia have also reportedly displayed neurologic improvement following bolstering of cardiac function with chronotropic [24, 32] and inotropic [3, 15, 24] agents and with therapeutic reversal of congestive heart failure [20], though detailed investigations of cardiac function were seldom carried out in these patients. These observations on cardiac function and its possible relationship to cerebral perfusion prompted us to perform this controlled study in which we weighed the relative importance of changes in cardiac function with changes in blood viscosity when the colloid agent, dextran, is used for therapy of focal ccrebral ischemia.

The influences of cardiac output on cerebral blood flow in anesthetized cats was studied in detail by Davis and Sundt [5], and they discovered that normal brain is capable of autoregulating its flow to cardiac output increases induced by hypervolemia with albumin. However, decreases in cardiac output induced by hypovolemia produced small but significant decreases in global CBF. The studies of McGillicuddy et al. [18] in monkeys also confirmed that nonischemic brain is capable of maintaining a stable blood flow in response to hypervolemia induced by dextran infusion. The results of our study suggest that blood flow to nonischemic brain remains stable both in response to cardiac output augmentation with hypervolemia and to isovolemic hemodilution.

Several animal and human studies have investigated the response of ischemic brain to administration of colloid agents. Cyrus et al. [4] performed a series of controlled experiments in dogs which underwent a 2-hr MCA occlusion and found that animals which were given large doses of intravenous $10 \%$ Dextran $40(15 \mathrm{ml} / \mathrm{kg})$ prior to occlusion experienced much smaller areas of infarction and minimal neurological damage when compared to animals which received no treatment. These in- vestigators attributed their results to prevention of microcirculatory obstruction from dextran's hypothetical "anti-sludging" effects. McGillicuddy et al. [18] found that infusions of dextran following induction of vasospasm in the middle cerebral artery in monkeys brought about increases in local CBF to the ischemic brain region, though not to a nonischemic one. Heiss [9] reported that dextran infusion in humans could bring about selective increases in regional $\mathrm{CBF}$ to ischemic brain regions while blood flow is decreased to nonischemic regions. In another study, dextran infusion after periods of total circulatory arrest in dogs appeared to improve local CBF and EEG recovery [16].

The concept of beneficial effect of hemodilution caused by administration of colloid solutions in cerebral ischemia was expounded by the report of Wood et al. [30]. They found that an area of focal cerebral ischemia in dogs responded to infusions of plasma and of dextran with significant increases in local CBF. Mean infarct size was also dramatically reduced in animals undergoing volume expansion with these colloid agents. Autologous whole blood infusions failed to produce either significant changes in local CBF to ischemic regions or reduction of infarct size, however $[30,31]$. They concluded that "hypervolemic hemodilution" was the mechanism responsible for these beneficial results. Cardiac output was increased in all dogs undergoing volume expansion, though much less so in those treated with whole blood transfusions $(+58 \%)$ than in those receiving plasma $(+100 \%)$, or dextran $(+114 \%)$. These authors tended to ignore the relative contribution of cardiac output to their observed results and instead postulated a direct effect of lowered blood viscosity on local CBF despite the fact that no strict control studies involving hemodilution without changes in cardiac output were performed.

Our study tends to show that cardiac output augmentation, rather than hemodilution and lowered blood viscosity alone is the most important factor in producing the observed effects on local blood flow to ischemic brain regions when intravascular volume expansion 
with colloid is employed. How volume expansion with cardiac output augmentation are able to achieve these results remains to be elucidated, though it stands to reason that collateral circulation to the area of brain normally supplied by an occluded artery is somehow augmented when systemic circulatory activity is increased. Perhaps vascular resistance in these collateral vessels is lowered as it is in other organs of the body when cardiac output is increased by intravascular volume expansion. An autoregulating vascular bed is capable of resisting changes in cardiac output, but it is possible that areas with impaired autoregulation in the periphery of an ischemic focus are unable to resist such changes in cardiac output, just as they are unable to resist changes in perfusion pressure [26]. Lowering of cardiac output occurring with diuresis or with the production of congestive heart failure in our studies brought about selective decreases in local blood flow to ischemic regions, and improvement of cardiac output with appropriate medical treatment brought about prompt recovery of blood flow to these regions. Hematocrit was not significantly changed during these episodes so it would be difficult to ascribe these changes to an alteration in blood viscosity. Pritz and Kindt [20] reported one patient with cerebrovascular disease whose clinical status seemed to vary directly with cardiac status, his condition deteriorating at low cardiac output states occurring with extremes of hydration, i.e., hypovolemia and congestive heart failure.

Our animals usually displayed step-wise increases in cardiac output during the course of volume expansion with dextran. No such stepwise increases in either local CBF or in cardiac output were observed when isovolemic hemodilution with dextran was employed in control studies. Wood et al. [31] state that the failure of their dogs to respond to whole blood infusions with significant increases in local CBF discounts a relationship of cardiac output and cerebral blood flow. However, the increases in cardiac output in their animals in that study and in a previous study [30] averaged only 42 and $59 \%$. Perhaps the changes in local CBF in our animals at those levels of cardiac output increase would not have reached statistical significance either, but the progressive increase in local CBF to levels reached at maximal cardiac output did achieve statistical significance as did the results observed in the studies of Wood et al. [30] when cardiac output increases similar to those achieved in our studies (greater than 100\%) were achieved by infusion of plasma or dextran.

The finding of a differential response in two areas within an ischemic focus in our animals is quite interesting. Though the convexity region often responded similarly to the opercular region, increases in local CBF were not as marked or as consistent in the convexity, this being reflected by a large standard deviation and lack of statistical significance which could be ascribed to the results in that arca. Thesc findings could be a reflection of two factors. Either the convexity region possesses fewer collaterals, or less consistent collateral circulation than does the operculum, or else the sample size is too small.

The concept of "ischemic threshold" also deserves some comment in relation to this study's results. Although many of our postocclusive local CBF values in areas of supposedly ischemic cortex were somewhat above the levels of 15 to $23 \mathrm{ml} / 100 \mathrm{~g} / \mathrm{min}$ ("ischemic threshold" as reported in monkeys by several investigators $[1,2,11]$ ), areas registering postocclusive blood flow below these levels usually responded to volume expansion with increases in local CBF to levels above this supposed "ischemic threshold." This would imply that volume expansion would have therapeutic benefit in the eventual outcome of these animals, although clinical neurologic status and infarction volumes were not observed.

The results of our study tend to support the tenet that intravascular volume expansion may be a useful adjunct to treatment of cerebrovascular insufficiency $[12,18,19,29]$. The authors have also found this to be the case in a number of ischemic stroke patients with carotid occlusive disease, especially if clinical dehydration or hypovolemia is present 
at the onset of neurologic deterioration (unpublished data). Our finding that regions of focal cerebral ischemia are selectively vulnerable to alterations in cardiac output upholds the hypothesis set forth by Vander Ark and Pomerantz [32] and by Pritz and Kindt [20] that cardiac output control may be vital to treatment of cerebral ischemia. Primary blood viscosity reduction without augmentation of cardiac output by hypervolemia was ineffective in our studies and tends to discount the hypothesis set forth by other investigators that hemodilution per se is the primary objective and determinant to be followed in treatment of ischemic cerebrovascular disease. The relative contribution of blood viscosity changes induced by colloid infusions during intravascular volume expansion will require further meticulous laboratory investigation.

\section{ACKNOWLEDGMENTS}

This investigation was supported by funds from the Section of Neurosurgery at the University of Michigan. The authors express their gratitude to Mr. Kent Wilber for his superb engineering assistance.

\section{REFERENCES}

1. Astrup, J., Symon, L., Branston, N. M., and Lassen, N. A. Cortical evoked potential and extracellular K+ and $\mathrm{H}+$ at critical levels of brain ischemia. Stroke $\mathbf{8}$ : $51,1977$.

2. Branston, N. M., Symon, L., and Crockard, H. A. Recovery of the cortical evoked response following temporary middle cerebral artery occlusion in baboons: Relation to local blood flow and pO2. Stroke 7: $151,1976$.

3. Brown, F. D., Hanlon, K., and Mullan, S. Treatment of aneurysmal hemiplegia with dopamine and mannitol. J. Neurosurg. 49: 525, 1978.

4. Cyrus, A. E., Close, A. S., Foster, L. L., Brown, D. A., and Ellison, E. H. Effect of low molecular weight dextran on infarction after experimental occlusion of the middle cerebral artery. Surgery 52: 25, 1962.

5. Davis, D. H., and Sundt, T. M., Jr. Relationship of cerebral blood flow to cardiac output, mean arterial pressure, blood volume, and alpha and beta blockade in cats. J. Neurosurg. 52: 745, 1980.

6. Frank, O. Zur dynamik des herzmuskels. Z. Biol. 32: $370,1895$.

7. Gilroy, J., Barnhart, M. I., and Meyer, J. S. Treatment of acute stroke with dextran-40. J. Amer. Med. Assoc. 210: 293, 1969.

8. Haggendal, E., and Norback, B. Effect of viscosity on cerebral blood flow. Acta Chir. Scand. Suppl. 364: 13, 1966.

9. Heiss, W. Effect of drugs on cerebral blood flow in man. Adv. Neurol. 25: 95, 1979.

10. Hudgins, W. R., and Garcia, J. H. Transorbital approach to the middle cerebral artery of the squirrel monkey: A technique for experimental cerebral infarction applicable to ultrastructural studies. Stroke 1: $107,1970$.

11. Jones, T. H., Morawetz, R. B., Crowell, R. M., et al. Thresholds of focal cerebral ischemia in awake monkeys. J. Neurosurg. 54: 773, 1981.

12. Kassell, N. F., Peerless, S .J., Durward, Q. J., Beck, D. W., Drake, C. G., and Adams, H. P. Treatment of ischemic deficits from vasospasm with intravascular volume expansion and induced arterial hypertension. Neurosurgery 11: 337, 1982.

13. Kudo, T., Suzuki, S., and Iwabuchi, T. Importance of monitoring the circulating blood volume in patients with cerebral vasospasm after subarachnoid hemorrhagc. Neurosurgery 9: 514, 1981.

14. Laha, R. K., Israeli, J., Dujavny, M., Barrisnuevo, P. J., and Heltstrom, H. R. Low molecular weight dextran in experimental embolectomy. Stroke 11: 59, 1980.

15. Levy, W. J., Bay, J. W., Sawhny, B., and Tank, T. Aminophylline plus nitroprusside and dopamine for treatment of cerebral vasospasm. A preliminary report. J. Neurosurg. 56: 646, 1982.

16. Lin, S., O'Connor, M. J., King, A., Harnish, P., and Fischer, H. W. Effect of dextran on cerebral function and blood flow after cardiac arrest. An experimental study on the dog. Stroke 10: 13, 1979.

17. Little, J. R., Slugg, R. M., Latchaw, J. P., and Lesser, R.P. Treatment of acute focal cerebral ischemia with concentrated albumin. Neurosurgery 9: 552, 1981.

18. McGillicuddy, J. E., Kindt, G. W., and Keller, T. S. The effect of intravascular volume expansion on blood flow in ischemic brain. A clinical and laboratory study. In J. Cervos-Navarro and E. Fritschka (Eds), Cerebral Microcirculation and Metabolism. New York: Raven Press, 1981. Pp. 415-419.

19. Pritz, M. B., Giannotta, S. L., Kindt, G. W., McGillicuddy, J. E., and Prager, R. L. Treatment of patients with neurological deficits associated with cerebral vasospasm by intravascular volume expansion. Neurosurgery 3: 364, 1978.

20. Pritz, M. B., and Kindt, G. W. Transient neurologic deficits associated with congestive heart failure and hypovolemia. Surg. Neurol. 15: 467, 1981.

21. Starling, E. H. Linacre Lecture on Law of the Heart. London: Longmans, Green, 1918.

22. Sundt, T. M., Jr. Comments. Neurosurgery 4: 225 , 1979.

23. Sundt, T. M., Jr., Grant, W. C., and Garcia, J. H. Restoration of middle cerebral artery flow in experimental infarction. J. Neurosurg. 31: 311 , 1969.

24. Sundt, T. M., Jr., Onofrio, B. M., and Meredith, J. Treatment of cerebral vasospasm from subarachnoid 
hemorrhage with isoproterenol and lidocaine hydrochloride. J. Neurosurg. 38: 557, 1973.

25. Sundt, T. M., Jr., Waltz, A. G., and Sayre, G. P. Experimental cerebral infarction: Modification by treatment with hemodiluting, hemoconcentrating, and dehydrating agents. J. Neurosurg. 26: 46, 1967.

26. Symon, L., Branston, N. M., and Strong, A. J. Autoregulation in acute focal ischemia. An experimental study. Stroke 7: 547, 1976.

27. Symon, L., Pasztor, E., and Branston, N. M. The distribution and density of reduced cerebral blood flow following acute middle cerebral artery occlusion: An experimental study by the technique of hydrogen clearance in baboons. Stroke 5: 355, 1974.

28. Willis, J. A., Doyle, T. F., Ramirez, A., Kobrine, A. I., and Martins, A. N. A practical circuit for hydrogen clcarance in blood flow measurement. TN74-
2. Washington, D. C.: Armed Forces Radiation Research Institute, 1974.

29. Wood, J. H., and Fleischer, A. S. Observations during hypervolemic hemodilution of patients with acute focal cerebral ischemia. J. Amer. Med. Assoc. 248: 2999, 1982.

30. Wood, J. H., Simeone, F. A., Snyder, L. L., Fink, E. A., and Golden, M. A. Hemodilutional and nonhemodilutional hypervolemia in treatment of focal cerebral ischemia. J. CBF. Metab. 1(Suppl.): S178, 1981.

31. Wood, J. H., Snyder, L. L., and Simeone, F. A. Failure of intravascular volume expansion without hemodilution to elevate cortical blood flow in region of experimental focal ischemia. J. Neurosurg. 56: 80, 1982.

32. Vander Ark, G. D., and Pomerantz, M. Reversal of ischemic neurological signs by increasing the cardiac output. Surg. Neurol. 1: 257, 1973. 